\title{
Epidemiology of tinnitus: (1) Prevalence
}

by

\author{
R. R. A. COLEs, M.R.C.P. (MRC Institute of Hearing Research, University Park, \\ Nottingham NG7 2RD, England)
}

To allocate sufficient resources to clinical services or to research and development in the most effective way possible, statistics are needed on the prevalence of the condition in question for various degrees of severity. For the United Kingdom, such data for tinnitus have become available from two recent large-scale studies. The first is the National Study of Hearing (NSH) which is being conducted by the Medical Research Council's Institute of Hearing Research from its headquarters in Nottingham and its clinical outstations in Cardiff, Glasgow, Nottingham and Southampton. It started in 1978 and is now entering its third phase. The second study is the General Household Survey carried out in 1981 by the UK Office of Population Censuses and Surveys (OPCS). The rationale and methodology of the NSH and the prevalence data obtained up to the present, together with those from the OPCS survey, will be given in this paper; the demographic data and the clinical aspects

The material of this paper was presented at the Seminar and prepared for publication by Dr. R. R. A. Coles. Data analysis was carried out by A. C. Davis, Heather Fortnum, N. Longford, Anne Sempik and Pauline Smith. The main planning, coordination and management of the IHR multicentre studies described was the responsibility of A. C. Davis and M. P. Haggard. The senior field investigators were: at Cardiff, J. A. B. Thomas and R. J. Rendell (and formerly J. J. Miller); at Glasgow, G. G. Browning, S. Gatehouse and R. Pollock; at Nottingham, J. F. Neil, M. E. Lutman, Pauline Smith and Susan Robinson (and formerly P. H. Beales, K. P. Gibbin, B. Majumdah and R. S. Tyler); at Southampton, P. B. Asheroft, A. R. D. Thornton and I. E. Bell (and formerly A. SeymourJones). of the study will be presented in the accompanying paper (IHR, 1984).

\section{National Study of Hearing}

The NSH is a multi-purpose study of hearing and its disorders (including tinnitus) in the population covering normal function, pathology and possible pathological influences, impairment, disability and handicap. It is providing prevalence data for the planning purposes mentioned, and also control data for other studies by suitably matching such important variables as age, gender, noise exposure, socioeconomic group and other demographic variables. Thirdly, the influence of these and other demographic variables on prevalence of hearing impairment and tinnitus in the population is being studied. Fourthly, a large number of specific hypotheses will be tested, each one of which would demand a considerable scale of research effort; but in a large multivariate study adding the relevant variables for each such hypothesis increases only slightly the overall complexity and cost. Fifthly, having population-based samples of persons with and without hearing disorder, all thoroughly investigated and computerdocumented, provides an invaluable base for further studies, notably in the psychoacoustics field. Finally, the study is now moving into a longitudinal phase from which it is hoped that present and developing determinants of hearing impairment and tinnitus may be identified.

Thus, the present data on the prevalence of tinnitus and its demographic and clinical 
features have to be seen in context as part of a much larger and more comprehensive study. Much analysis work remains to be done, and further data are yet to be collected, but useful material is already available and some of it is presented here.

The basic plan of the study is shown in Fig. 1. The initial sampling (Tier $\mathrm{A}$ ) is at random from the electoral registers of the four cities in which the Institute has its outstations; Cardiff, Glasgow, Nottingham and Southampton. The postal questionnaire is short and simple, to produce high response rates ( 81 per cent, after up to two reminders). It enables the respondents to be stratified by self-reported hearing state (no complaint, hearing disorder, tinnitus, and hearing disorder plus tinnitus), age, gender, occupational noise exposure, and hearing-aid possession. This doublesampling improves the efficiency of the subsequent prevalence estimates and other data obtained from the more intensive in-

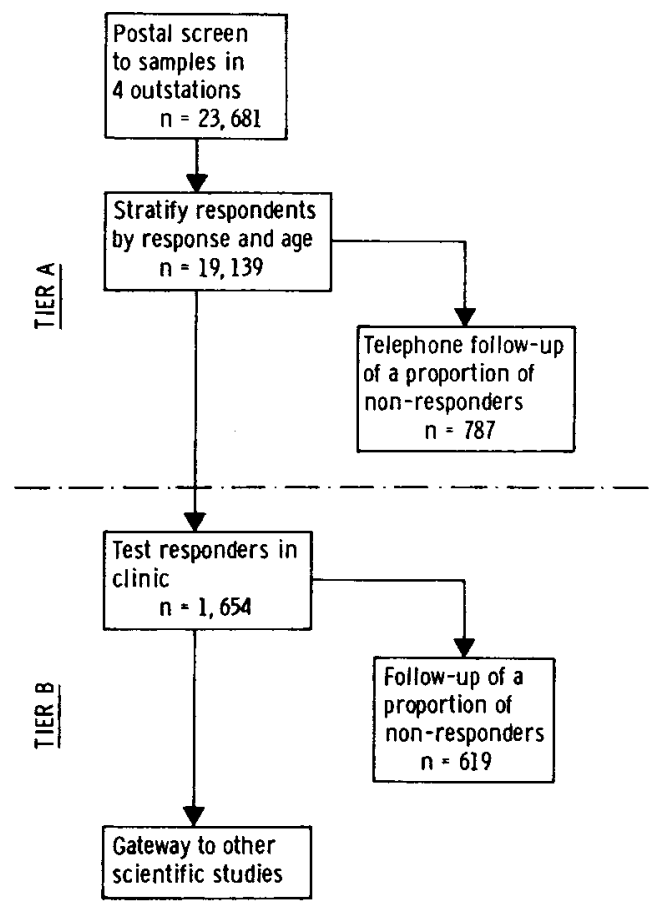

FIG. 1

Plan of National Study of Hearing, Phases I and II. clinic investigations (Tier B). A telephone follow-up of a proportion of the remaining non-responders is made to check on possible biases. Up to now, these have been quite small, and can be allowed for in the eventual whole-population prevalence estimates.

The acceptance rate of those subsequently invited to come into the clinic has been about 50 per cent. Domiciliary followup, including simple audiometry is carried out to check on possible biases in the nonaccepters. Again, these biases have been minimal, apart from a suspected low compliance rate from ethnic-minority immigrants, which will be further studied.

In the clinic (Tier B), an otological examination is performed together with a detailed clinical history of otological and general physical disorders, drugs taken, and other possible aetiological factors past and present. In the first two phases, blood samples were taken for haematology, general blood chemistry, liver, thyroid and renal function tests, and syphilis serology. Conventional audiometric tests are carried out including tympanometry and acoustic reflex measurements. The core of medical and audiometric assessment is supplemented by a range of further tests, which have varied from phase to phase but typically include tests of frequency resolution and of audio-visual speech communication ability together with specific conditional tests, notably those on tinnitus when it is present.

As will be seen later, the various figures for different degrees of tinnitus cover a wide range, and it is therefore critically important to note exactly what questions were asked, what were the response alternatives, and how were the questions administered. (The tinnitus questions and response alternatives in the Tier A postal questionnaires are given in the Annex to this paper). There is no single condition of 'tinnitus' that can be given a fixed definition and a single prevalence figure. There is a series of figures depending on the descriptions of the severity of the tinnitus.

The overall time scale of the various 


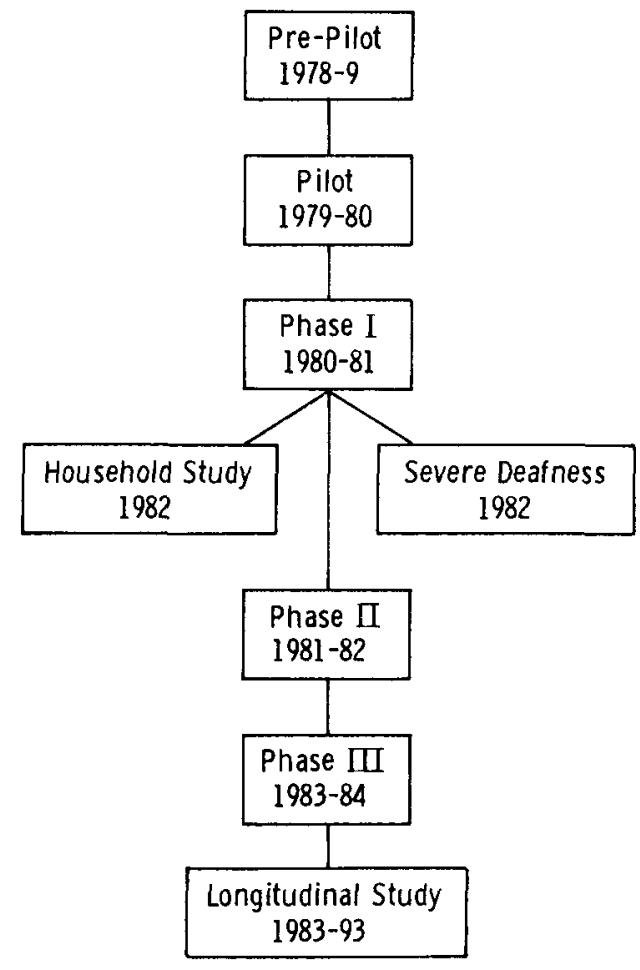

FIG. 2

Components and time scale of National Study of Hearing.

components of the NSH is shown in Fig. 2. The aims, design and test complements of the NSH from Pre-Pilot to Longitudinal Study have already been described. The Household Study was also conducted in two tiers, but based entirely on domiciliary visiting for Tier $\mathrm{B}$. The sampling frame was households from the Post Office list of postal addresses. The districts covered were spread widely through the UK and were selected according to housing type, giving a residential rather than economic indication of social class. Its purpose was both to complement the individual-person based data provided by the other phases, and also to ascertain the degree to which estimated prevalences for the four outstation cities may be applicable to the whole population, including those living in rural areas.

The Severe Deafness Study attempts to enumerate the prevalence of total and severe deafness in the population, and is being carried out by an inventory procedure going through all the relevant care agencies, e.g., general practitioners, otolaryngologists, social services staff. This is being done throughout the Wessex Health Region, which has about 2.5 million persons in it, with Southampton close to its centre. There is also some additional Tier A sampling in Phase III of the NSH for Southampton. This study will give information on the amount and severity of tinnitus in the severely deaf population, and will offer numerical bases for estimating requirements for rehabilitation with cochlear implants in profound deafness or possibly for electrical stimulation of the cochlea as a treatment for tinnitus associated with severe deafness.

\section{Pre-Pilot Study}

This was carried out in Glasgow in 1978-79, primarily to try out some of the survey questionnaires and methods. It included a postal questionnaire to a random sample of 522 persons. Interestingly, no less than 39 per cent answered 'Yes' to the general question "have you ever noticed noises in your head or ears?". This is similar to a question asked by Hinchcliffe in 1961 in his study of a random sample of 800 persons in two rural communities when, in different age groups, some 21-39 per cent answered 'Yes'.

\section{Pilot Phase}

Pilot Phase data on the prevalences of tinnitus in varying degrees in the four cities, and on some of its demographic variables, have already been published (IHR, 1981a, b); some of the previously published material is repeated in the present two papers for sake of their completeness and to facilitate comparison with results of Phases I and II not previously reported. Note that those with tinnitus of 'less than five minutes duration' and when the tinnitus is experienced 'just after very loud sounds, e.g. discos, shooting, or noise at work' had 
TABLE I

NATIONAL STLDY OF HEARING, PILOT PHASE: TINNITUS PREVALENCES BY CITY (6804 persons surveyed at Tier A. 5000 usable responses, $73.5 \%$ )

\begin{tabular}{|c|c|c|c|c|}
\hline & Cardiff & Glasgow & Nottingham & Southampton \\
\hline \multicolumn{5}{|l|}{ Percentages with: } \\
\hline Tinnitus* & 17.9 & 18.6 & 18.1 & 15.5 \\
\hline $\begin{array}{c}\text { Annoyance: } \\
\text { Moderate } \\
\text { Severe }\end{array}$ & $\begin{array}{l}4.1 \\
0.7\end{array}$ & $\begin{array}{l}4.1 \\
2.8\end{array}$ & $\begin{array}{l}4.4 \\
0.4\end{array}$ & $\begin{array}{l}3.8 \\
0.7\end{array}$ \\
\hline Sleep disturbance & 3.8 & 7.3 & 5.4 & 4.4 \\
\hline $\begin{array}{l}\text { Severe effect on ability to } \\
\text { lead a normal life }\end{array}$ & 0.4 & 0.5 & 0.4 & 0.5 \\
\hline
\end{tabular}

* The question excluded those with short-duration and temporary noise-induced tinnitus.

already been excluded from the tinnitus questions asked in the Pilot Phase (see Annex, Pilot Phase, introductory sentences). Thus, the 15.5-18.6 per cent prevalence rate shown in Table I concerns 'spontaneous' tinnitus of over five minutes duration. (Note: Here, and elsewhere in this paper, the word 'spontaneous' refers to all forms of tinnitus other than temporary tinnitus experienced immediately after noise exposure).

It can be seen that tinnitus causing a moderate degree of annoyance is reported by about 4 per cent, with a further 1 per cent reporting severe annoyance. Interference with 'getting to sleep' was reported by about 5 per cent. Tinnitus having a severe effect on 'ability to lead a normal life' is reported by about 0.5 per cent.

Cross-tabulations of Pilot Study data (IHR, 1981b) showed that only about four fifths of those reporting moderate to severe annoyance from their tinnitus, or severe effects on their ability to lead a normal life, reported specifically that tinnitus interfered with their getting to sleep. This has some clinical importance as a warning not to rely solely on a history of sleep disturbance as an indicator of severity of tinnitus, as appears to be a quite common clinical practice. Likewise the severity of tinnitus is sometimes judged by whether it is present continuously or intermittently. In Phase II (Tier B data) we had the opportunity to study the relationship between this and tinnitus annoyance. Of the 71 persons with continuous tinnitus in that sample, 36 reported it as annoying, and 35 as not annoying. Of the 104 persons with intermittent tinnitus, 51 reported it as annoying and 53 as not annoying. Clearly, whether a tinnitus is continuous or intermittent is no indicator at all as to its severity, as expressed in terms of the annoyance it causes. To judge the severity of tinnitus, description is needed of a whole range of possible effects, e.g. the degree of annoyance it causes, its interference with speech communication, mental processes and getting to sleep, and its effects on quality of life overall, and search should also be made for possible secondary psychiatric disturbances.

\section{Phases I and II}

The tinnitus prevalences in varying degrees of severity indicated by Phases I and II are shown in Table II, together with comparative data from the Pre-Pilot and Pilot Phases. The prevalence in the adult population of tinnitus of unrestricted type and duration is shown to be about 35 per cent.

In Phases I and II the prevalence estimates for 'spontaneous' tinnitus of duration over five minutes was derived from those who responded positively to the 
TABLE II

POPULATION PREVALENCES $(\%)$ FOR SEVERAL QUALIFICATIONS OF THE TINNITUS REPORTED IN THE TIER A QUESTIONNAIRES IN FOUR PHASES OF THE NATIONAL STUDY OF HEARING

(Combined data from the Cardiff, Glasgow, Nottingham and Southampton random samples).

\begin{tabular}{|c|c|c|c|c|}
\hline & Pre-Pilot & Pilot & Phase I & Phase II \\
\hline (n, usable) & $(522)$ & $(5000)$ & $(8069)^{(a)}$ & $(7645)^{(a)}$ \\
\hline Tinnitus (any type) & 39 & - & 38.0 & 33.8 \\
\hline $\begin{array}{l}\text { Tinnitus ( }<5 \text { ' and /or } \\
\text { 'non-spont.') }\end{array}$ & - & - & 27.0 & 23.2 \\
\hline $\begin{array}{l}\text { Diff. }(=\text { 'spont. tinn.' } \\
\left.10.6^{(b)}>5^{\prime}\right)\end{array}$ & - & - & $11.0^{(\mathrm{b})}$ & $1.06^{(\mathrm{b})}$ \\
\hline $\begin{array}{l}\text { Tinn. ( }>5 \text { ' and } \\
\text { 'spontaneous') } \\
\text { Interference with getting }\end{array}$ & - & $17.5^{(\mathrm{b})}$ & - & - \\
\hline to sleep & - & 5.6 & 7.4 & 7.0 \\
\hline Mod./Sev. annoyance & - & 5.7 & 8.1 & 8.7 \\
\hline Severe effect on quality & - & - & - & 1.0 \\
\hline Severe effect on ability & - & 0.5 & - & - \\
\hline
\end{tabular}

(a) In the Glasgow samples, the over 65 years age group was slightly under-estimated.

(b) Used as bases for data on influences of age, sex, noise, SEG and interactions with affect published in the accompanying paper (1HR, 1984).

first question (see Annex, Phases I and II, question B1) which concerned tinnitus of any type or duration, and remained after exclusion of those who responded to either of the next two questions (B2 and B3) which identified those with short-duration and 'non-spontaneous' tinnitus. In fact, in three quarters of those with 'non-spontaneous' tinnitus the tinnitus was also of duration less than five minutes. These differences in the way the questions were framed and analysed probably explain the apparent lower proportion of 'spontaneous' tinnitus of over five minutes duration found in Phases I and II as compared with the Pilot Phase. There were also slight changes in wording in the initial question (B1) between Phases I and II: Phase II gave greater emphasis to present than past tinnitus, but also allowed three response alternatives. These differences in wording probably underly the slightly lower prevalence figures, in Phase II as compared with Phase I, for tinnitus of any type and for tinnitus of short duration or 'non-spontaneous' type.

There were slightly greater prevalences of reported interference with getting to sleep and of moderate or severe annoyance in Phases I and II as compared with the Pilot Phase. Recall that in the Pilot Phase, no further questions were asked if the tinnitus was of temporary noise-induced type or of under five minutes duration. It would therefore seem likely that some of the 'non-spontaneous' or short-duration tinnitus experiences excluded (in the Pilot Phase only) were in fact annoying and/or sleep interfering. That consideration apart, there is good agreement across phases.

A question on general effects on life was not asked in Phase I. It was re-inserted into Phase II, but expressed in terms of 'affect the quality of your life as a whole' (Phase II, question B7) rather than 'affect your ability to lead a normal life' (Pilot Phase, question $\mathrm{B} 3$ ). The corresponding prevalence rate shifts from 0.5 per cent to 1 per cent $(p=<0.01)$ with this change of wording, and in the expected direction.

In a recent review of earlier American surveys, Leske (1981) quotes a prevalence of 'severe tinnitus' of 5.6 per cent, which is supported now by the general pattern of prevalences for UK urban populations shown in Table II, lying somewhere between the prevalences of moderate and 
severe annoyance by tinnitus. She also reported the results of a question about experience of tinnitus of any type or duration that has occurred 'at any time over the past few years'. This gave a prevalence of 32 per cent, which is again in good agreement with the NSH data.

\section{Phase III}

In Phase III, apart from a common medical and audiometric core, the Tier B tests differ in order to accommodate more specialized sub-studies on particular topics. Those include the start of the Longitudinal Study, a study of hearing disorders in twins, specific studies of causes of hearing impairment and hearing disability, and of tinnitus. The tinnitus sub-study will obtain further data related to prevalence. It is looking in detail at the natural history of tinnitus, past and present, in terms of length of history, annoyance course and loudness course: on this, it is hoped that it will be possible to base more authoritative counselling of tinnitus patients. The study will also obtain data on the personality of persons reporting tinnitus and on the extent to which they have sought medical help.

\section{OPCS Study (1983)}

The General Household Survey is a multi-purpose survey carried out by the Office of Population Censuses and Surveys on behalf of a number of government departments. The GHS has been running continuously since 1971, collecting information by personal interview on a wide variety of topics. In 1981, a short series of questions on tinnitus was included at the request of the Department of Health and Social Security and responses to these were obtained (by personal interview) from more than 23,000 persons aged 16 and over.

The report reads: "Overall, 22 per cent of adults interviewed said that they had heard noises in their head or ears such as ringing or buzzing sounds. Subsequent questions established that in about one third of these informants the noises were brought on only by an external stimulus-a loud noise, water getting in the ears, or colds and catarrh". The wording of the questions with respect to severity was different from the $\mathrm{NSH}$, but the most relevant groups are probably those that said they were "bothered a great deal" or "bothered quite a lot"'. Two per cent of the population said 'Yes' to one or other of those questions. This is a lower figure than might have been expected from the NSH data, but the difference may be due to the fact that the OPCS study was done by personal interview, while the NSH study was based on postal questionnaire. On the other hand, the 5.6 per cent 'severe tinnitus' figure quoted by Leske (1981) was also based on interviews; compared with the OPCS result, it may reflect a higher prevalence of troublesome tinnitus in the United States of America, or possibly a difference in the way in which peoples of different national culture respond to specific questions.

\section{Population Projections}

The representations of the NSH samples to the general population of the UK is not yet certain, since analysis of our Household Study data is not complete. In generalizing to other countries, differences associated with climate, noise exposure of all types (occupational, military, leisure activities, domestic and community), different socioeconomic structure, race and diet have to be considered.

In spite of the many uncertain factors noted above, some projections from the NSH data obtained so far are probably worthwhile to indicate the general prevalences in the adult (age 17 and over) populations of industrialized countries, as follows:

About 35 per cent of adults appear to have experienced tinnitus of some type or duration at some time. Even the shortduration ones appear to be a nuisance to some of the 'sufferers'. It is also a possibility that short-duration tinnitus may have some prognostic significance with respect to later development of tinnitus. 
About 15 per cent of adults appear to have or to have had 'spontaneous' tinnitus lasting over five minutes duration.

At least 8 per cent experience tinnitus causing interference with their getting to sleep, and/or moderate or severe annoyance. If our samples are representative of the populations, this would suggest about four million adults in the UK being so affected, and 16 million in the USA.

At the top end of the spectrum of severity come those 0.5 per cent who report that their tinnitus has a severe effect on their ability to lead a normal life. As a percentage 0.5 per cent sounds small, but this amounts to about 200,000 persons in the UK and 800,000 in the USA. Moreover, tinnitus of this severity is at least comparable in terms of prevalence, of effects on health and quality of life, and of effectiveness of its treatment (be it counselling, rehabilitational, medical or even surgical) as many of the surgically treated conditions of the ear. It therefore deserves much greater clinical attention than it has usually received up to now.

\section{References}

HinchCLIfFE, R. (1961) Prevalence of the commoner ear, nose and throat conditions in the adult rural population of Great Britain. British Journal of Preventive and Social Medicine, 15: 128-140.

INSTITUTE OF HEARING RESEARCH (1981a) Epidemiology of tinnitus. In: Tinnitus. Ciba Foundation Symposium 85. Pitman Books, London, pp. 16-34.

INSTITUTE OF HEARING RESEARCH (1981b) Population study of hearing disorders in adults: preliminary communication. Journal of the Royal Society of Medicine, 74: 819-827.

INSTITUTE OF HEARING RESEARCH (1984) Epidemiology of tinnitus: (2) demographic and clinical features. Proceedings of the Second International Tinnitus Seminar, New York, 10-11 June, 1983. Published in this supplement.

LESKE, M. CRISTINA (1981) Prevalence estimates of communicative disorders in the US: language, learning and vestibular disorders. Asha, 23: 229-237.

OfFice of Population Censuses and Surveys (1983) General Household Survey: the prevalence of tinnitus, 1981. OPCS Monitor, Reference GHS 83/1, Information Branch (Dept M), OPCS, 10 Kingsway, London WC2B 6JP.

\section{ANNEX}

\section{TINNITUS SECTIONS IN TIER A POSTAL QUESTIONNAIRE}

\section{PILOT PHASE}

In this section we are interested in whether you get ringing or buzzing noises in your head or ears. The occasional whistling or ringing in the ears of less than five minutes duration should not be counted. Also do not count those times when this happens just after very loud sounds, e.g. discos, shooting, or noise at work.

If you DO NOT get noises in your head or ears turn to SECTION C.

B1. Where do you most commonly hear buzzing or ringing in your head or ears?
a. IN THE LEFT EAR
b. IN THE RIGHT EAR
c. IN BOTH EARS
d. IN THE HEAD

B2. Indicate how annoying you find noises in your head or ears.
a. NOT ANNOYING AT ALL
b. ANNOYING TO A SLIGHT DEGREE
c. ANNOYING TO A MODERATE DEGREE
d. ANNOYING TO A SEVERE DEGREE

B3. Indicate to what extent noises in your head or ears affect your ability to lead a normal life.
a. NOT AT ALL
b. TO A SLIGHT DEGREE
c. TO A MODERATE DEGREE
d. TO A SEVERE DEGREE

B4. Do you ever get a buzzing or ringing noise in your head or ears that interferes with your getting to sleep?

$$
\text { YES NO }
$$


PHASE I

In this section we are interested in whether you get noises in your head or ears such as ringing or buzzing.

B1. Do you ever get any noises in your head or ears?

YES

NO

If you never get noises in your head or ears please go to Section $C$.

B2. Do these noises usually last for longer than five minutes?

YES

NO

B3. Do you hear these noises only following very loud sounds (e.g. discos, shooting or noise at work)?
a. AFTER LOUD SOUNDS ONLY
b. AT OTHER TIMES ONLY
c. BOTH AFTER LOUD SOUNDS AND AT OTHER TIMES

B4. In which ear are you most affected by these noises?
a. MOSTLY IN THE LEFT EAR
b. MOSTLY IN THE RIGHT EAR
c. EQUALLY IN BOTH EARS OR IN THE HEAD

B5. Indicate how the noises in your head or ears change when you are in a noisy place.
a. THEY BECOME MORE NOTICEABLE
b. THEY STAY ABOUT THE SAME
c. THEY BECOME LESS NOTICEABLE

B6. Indicate how annoying you find the noises in your head or ears.
a. NOT ANNOYING AT ALL
b. SLIGHTLY ANNOYING
c. MODERATELY ANNOYING
d. SEVERELY ANNOYING

B7. Do the noises in your head or ears every interfere with your getting to sleep?

$$
\text { YES NO }
$$

PHASE II

In this section we are interested in whether you get noises in your head or ears such as ringing or buzzing.

B1. Nowadays do you ever get noises in your head or ears?
a. YES, MOST OF THE TIME
b. YES, SOME OF THE TIME
c. $\mathrm{NO}$

If you do not get noises in your head or ears place go to Section $C$.

B2. Do these noises usually last for longer than five minutes?

$$
\text { YES NO }
$$

B3. Do you hear these noises only following very loud sounds (e.g. discos, shooting, noise at work)?
a. ONLY AFTER LOUD SOUNDS
b. ONLY AT OTHER TIMES
c. BOTH AFTER LOUD SOUNDS AND AT OTHER TIMES

B4. In which ear are you most affected by these noises?
a. MOSTLY IN THE LEFT EAR
b. MOSTLY IN THE RIGHT EAR
c. EQUALLY IN BOTH EARS OR IN THE HEAD

B5. Indicate how the noises in your head or ears change when you are in a noisy place.
a. THEY BECOME MORE NOTICEABLE
b. THEY STAY ABOUT THE SAME
c. THEY BECOME LESS NOTICEABLE

B6. Indicate how annoying you find the noises in your head or ears when they are at their loudest.
a. NOT ANNOYING AT ALL
b. SLIGHTLY ANNOYING
c. MODERATELY ANNOYING
d. SEVERELY ANNOYING 
B7. Indicate to what extent the noises in your head or ears affect the quality of your life as a whole.
a. NOT AT ALL
b. TO A SLIGHT DEGREE
c. TO A MODERATE DEGREE

\section{d. TO A SEVERE DEGREE}

B8. Do the noises in your head or ears ever interfere with your getting to sleep?

YES NO

